\title{
Cardio-Renal Syndrome: Epidemiological Aspect in the Medicine Department of Tombouctou Hospital
}

\author{
Bassirima Traore ${ }^{1}$, Samba Sidibé2, Souleymane Mariko1, Karamoko Kantako1, \\ Massama Konaté ${ }^{3}$, Kalifa Diallo², Nouhoum Diallo², Mariam Sako², Abdoul Karim Sacko², \\ Youssouf Kassambara ${ }^{1}$, Ichaka Menta ${ }^{4}$, Souleymane Coulibaly ${ }^{2}$
}

${ }^{1}$ Department of Medicine, Tombouctou Hospital, Tombouctou, Mali

${ }^{2}$ Cardiology Department of the Point G University Hospital, Bamako, Mali

${ }^{3}$ Cardiology Department, Mali Hospital, Bamako, Mali

${ }^{4}$ Cardiology Department CHU Gabriel TOURE, Bamako, Mali

Email: t.bassirima@yahoo.fr

How to cite this paper: Traore, B., Sidibé, S., Mariko, S., Kantako, K., Konaté, M., Diallo, K., Diallo, N., Sako, M., Sacko, A.K., Kassambara, Y., Menta, I. and Coulibaly, S. (2022) Cardio-Renal Syndrome: Epidemiological Aspect in the Medicine Department of Tombouctou Hospital. World Journal of Cardiovascular Diseases, 12, 123-132. https://doi.org/10.4236/wjcd.2022.122013

Received: January 9, 2022

Accepted: February 22, 2022

Published: February 25, 2022

Copyright $\odot 2022$ by author(s) and Scientific Research Publishing Inc. This work is licensed under the Creative Commons Attribution International License (CC BY 4.0).

http://creativecommons.org/licenses/by/4.0/ (c) (i) Open Access

\begin{abstract}
Introduction: Cardio-renal syndrome is a pathophysiological disorder of the heart and kidneys in which chronic or acute dysfunction of one can lead to chronic or acute dysfunction of the other. The objective of this study was to determine the prevalence of cardio-renal syndrome in the Medical Department of the Tombouctou Hospital in Mali. Methods: It is about a descriptive transversal study carried out over 18 months, from January $01^{\text {st }}, 2020$ to June $30^{\text {th }}, 2021$ and relating to the analysis of 75 files of patients hospitalized for heart failure and with impaired renal function. Results: The frequency of cardio-renal syndrome was $6.4 \%$ with a predominance of men (sex ratio: 2 ). Hypertension was the most widely described risk factor (50.6\%). The history was dominated by chronic heart failure (14.6\%) and diabetes (6.6\%). The average age was 58 with extremes of 18 and 90 . The main aetiologies were dilated cardiomyopathy (46.6\%) and ischemic heart disease (20\%). Symptoms were dominated by dyspnea (90.6\%) and edema of the lower limbs and face (74.6\%) accompanied by cough (74.6\%). Anemia was noted in 15 patients (20\%). The mean clearance (MDRD) was at $32 \mathrm{ml} / \mathrm{min}$. Doppler echocardiography found left ventricular dilation (66.6\%), lower left ventricular systolic fraction (64\%) and kinetic abnormalities (20\%). The kidney ultrasound performed in 9 patients returned to normal in 8 cases and in 1 patient the kidneys were small. Eight deaths (10.6\%) were noted. Conclusion: Cardio-renal syndrome is a common feature in which mixed failure is observed in the unfavorable course of heart disease and nephropathy. Its prevalence is unfortunately under evaluated in cardiological settings in Africa and particularly in Mali, hence the interest of a more advanced study.
\end{abstract}




\section{Keywords}

Cardio-Renal Syndrome, Epidemiology, Tombouctou Hospital

\section{Introduction}

Cardio-renal syndrome is a pathophysiological disorder of the heart and kidneys in which chronic or acute dysfunction of one can lead to chronic or acute dysfunction of the other [1]. Cardio-renal syndrome is classified by Ronco [2] into five subtypes (Table 1 ).

His diagnosis is made on the basis of a picture of clinical heart failure with impaired renal function.

According to the US ADHERE registry, at least $65 \%$ of patients with a picture of acute heart failure have a creatinine clearance $<60 \mathrm{ml} / \mathrm{min}$ [3].

In Africa, the prevalence of the cardio-renal syndrome is little assessed in cardiology settings; in Senegal, a study conducted in a cardiology department in Dakar found 3.7\% [1].

In Mali, no study has dealt with this aspect of the cardio-renal syndrome, hence the interest of our study.

The objective of this work was to determine the hospital prevalence of cardio-renal syndrome in the Medical Department of the Tombouctou Hospital in Mali.

\section{Material and Method}

This was a descriptive transversal study carried out in the medical department of the Tombouctou hospital from January 2020 to June 2021, during which we included 75 patients with heart failure associated with impaired renal function.

Table 1. RONCO classification of cardio-renal syndrome.

\begin{tabular}{cl}
\hline TYPES & \multicolumn{1}{c}{ CHARACTERISTICS } \\
\hline Type 1 & $\begin{array}{l}\text { Acute CRS characterized by acute decompensated heart failure leading } \\
\text { to acute renal failure. }\end{array}$ \\
Type 2 & $\begin{array}{l}\text { Chronic CRS is characterized by chronic heart failure which leads to } \\
\text { chronic kidney disease. }\end{array}$ \\
Type 3 & $\begin{array}{l}\text { Acute reno-cardiac syndrome is due to acute renal failure which leads } \\
\text { to acute cardiac dysfunction, such as arrhythmia or heart failure. }\end{array}$ \\
Type 4 & $\begin{array}{l}\text { Chronic reno-cardiac syndrome is characterized by primary chronic } \\
\text { kidney disease that contributes to cardiac dysfunction. }\end{array}$ \\
Type 5 & $\begin{array}{l}\text { Also called secondary CRS where there is simultaneous renal and } \\
\text { cardiac involvement due to systemic disorders such as sepsis or } \\
\text { systemic lupus erythematosus. }\end{array}$ \\
\hline
\end{tabular}

CRS: Cardio-renal syndrome. 
The volunteers were patients hospitalized with heart failure and impaired kidney function. After obtaining informed consent, they were included in the study.

\subsection{Collection of Data}

Data collection was done from hospital records.

The data collected were socio-demographic, clinical (functional signs, physical signs), cardiovascular and para-clinical risk factors (trans-thoracic echocardiography, renal ultrasound, biological: blood count, glycemia, creatinemia, ionogramblood).

\subsection{Judging Criteria}

Clinical: patients with symptoms suggestive of heart failure.

The positive diagnosis of cardio-renal syndrome was based on:

- a clinical syndrome of heart failure,

- a serum creatinine greater than $1.4 \mathrm{mg} / \mathrm{dl}$ in women and $1.3 \mathrm{mg} / \mathrm{dl}$ in men.

Claudio Ronco's classification was used in this work.

\subsection{Operational Definitions}

Cardio-renal syndrome is a pathophysiological disorder of the heart and kidneys in which chronic or acute dysfunction of one can lead to chronic or acute dysfunction of the other.

Signs of heart failure (HF) were dyspnea (according to NYHA), crackling rales, left galloping noise for left HF and hepatalgia, right galloping noise, hepatomegaly, chest edema, lower limbs, the turgor of the jugular veins for the right CI. Renal impairment was considered for serum creatinine greater than 1.4 $\mathrm{mg} / \mathrm{dl}$ in women and $1.3 \mathrm{mg} / \mathrm{dl}$ in men.

\subsection{Variables}

Data were collected using the observational medical record and recorded in a questionnaire. This questionnaire was written by the scientific manager and the principal investigator and included.

The statistical population studied was patients with heart failure and impaired renal function.

The variables studied were:

- Quantitative includes the age of the patients, the seniority of hypertension and diabetes, the number of days of hospitalization and of deaths.

- Qualitative included the sex of the patients, symptoms, description of doppler echocardiographic abnormalities and biology. The questionnaire was submitted to a follow-up test on the recruitment procedure and data analysis.

The questionnaire was submitted to a daily quality control before being collected.

Excel 2016 software was used for data collection and then analyzed by SPSS 24 software. 


\subsection{Ethics}

Informed consent was obtained with strict respect for confidentiality.

\section{Results}

\subsection{The General Characteristics of the Studied Population}

Out of 1165 hospitalized patients, 75 had cardio-renal syndrome, including 25 women. The hospital prevalence was $6.4 \%$. The average age was 58 with extremes of 18 and 90. Chronic heart failure was the most common medical history (14.6\%) (Table 2). Cardiovascular risk factors were dominated by high blood pressure with $50.6 \%$. The mode of discovery was the table of global heart failure (74.6\%). The clinical symptoms were dominated by dyspnea (90.6\%) and edema of the lower limbs and face (74.6\%) accompanied by cough (74.6\%). Anemia was noted in 15 patients (20\%). The mean serum creatinine was $3.26 \mathrm{mg} / \mathrm{dl}$. The mean MDRD clearance at $32 \mathrm{ml} / \mathrm{min}$. Regular sinus tachycardia was the dominant abnormality on the EKG (42.6\%) followed by left ventricular hypertrophy (34.6\%) complete arrhythmia with atrial fibrillation (18.6\%). The left ventricular ejection fraction was studied by the teicholz method and there was a dilation of the left ventricle (66.6\%) associated with an alteration of the systolic function of the left ventricle (64\%). The kidney ultrasound performed in 9 patients returned to normal in 8 cases and in 1 patient the kidneys were small.

Chronic heart failure dominated the personal medical history (14.6\%) of frequency and global heart failure dominated the circumstances of discovery (74.6\%).

\subsection{Etiological Factors of CRS}

The etiologies of cardio-renal syndrome were dilated cardiomyopathy (46.6\%), ischemic heart disease (20\%), chronic renal failure (8\%), hypertrophic cardiomyopathy (2.6\%) and diabetes (2.6\%) (Table 3).

According to Ronco's classification, cardio-renal syndrome type 1 dominated (72\%) followed by type 2 (14.6\%) (Table 4 ).

Table 2. Distribution of patients according to personal medical history and the circumstances of discovery.

\begin{tabular}{ccc}
\hline Personal medical history & Effectives & Percentage (\%) \\
\hline Chronic heart failure & 11 & 14.6 \\
Diabetes & 5 & 6.6 \\
Chronic renal failure & 2 & 2.6 \\
HIV & 1 & 1.3 \\
\hline Circumstances of discovery & & \\
\hline Global heart failure & 56 & 16.6 \\
Left ventricular failure & 12 & 9 \\
Others & 7 &
\end{tabular}


Table 3. Distribution of patients according to etiological factors.

\begin{tabular}{ccc}
\hline Etiology & Effectives & Percentage (\%) \\
\hline Dilated cardiomyopathy & 35 & 46.6 \\
Ischemic heart disease & 15 & 20 \\
Chronic renal failure & 6 & 8 \\
Hypertrophic cardiomyopathy & 2 & 2.6 \\
Diabetes & 2 & 2.6 \\
Others & 10 & 13.3 \\
Total & 75 & 100 \\
\hline
\end{tabular}

Table 4. Distribution of patients according to the RONCO classification of cardio-renal syndrome.

\begin{tabular}{ccc}
\hline Classification & Effectives & Percentage (\%) \\
\hline Type 1 & 54 & 72 \\
Type 2 & 11 & 14.7 \\
Type 3 & 4 & 5.3 \\
Type 4 & 3 & 4 \\
Type 5 & 3 & 4 \\
Total & 75 & 100 \\
\hline
\end{tabular}

Dilated cardiomyopathy and ischemic heart disease dominated the etiologies with $46.6 \%$ and $20 \%$ frequency, respectively.

It was dominated by type 1 , i.e. (72\%).

\subsection{The Treatment}

All the patients benefited from treatment with a diuretic and a sodium-reduced diet. ACE inhibitors were prescribed in 69.3\% (52 patients), beta blockers in 18 patients (24\%) and calcium channel blockers in 16\% (12 patients).

\subsection{Hospital Evolution}

The duration of hospitalization was 5.4 days. The outcome was favorable in the majority of cases $(72 \%)$. Complications included $20 \%$ refractory heart failure, $8 \%$ dialysis and $2.6 \%$ cerebral embolism (2 cases). We recorded 8 deaths, i.e. $10.6 \%$ lethality. These were refractory heart failure $(20 \%)$ and stroke $(6.6 \%)$ Table 5.

\section{Discussion}

The prevalence of cardio-renal syndrome in our series is of the order of $6.4 \%$ higher than the $3.7 \%$ of the Dakar study [1] and lower than $65 \%$ according to the American ADHERE registry [3] be explained by the financial and security difficulties preventing patients not residing in the city of Tombouctou to consult. 
Table 5. Distribution of patients according to the type of complication under treatment.

\begin{tabular}{ccc}
\hline Complication & Effectives & Percentage (\%) \\
\hline Refractory heart failure & 15 & 20 \\
ACFA & 14 & 18.6 \\
Death & 8 & 10.6 \\
Chronic Renal Insufficiency with dialysis & 6 & 8 \\
Intracavitary thrombus & 5 & 6.6 \\
\hline
\end{tabular}

The average age was 58 years, higher than the $57.26 \pm 16.04$ years of kingue [4], but which remains relatively young by agreement in most African studies carried out on heart failure. Unlike in the West, this is a pathology in the subject aged around 70 years [5], this difference is explained by the early management of heart disease and nephropathy as well as risk factors in the West.

The male sex predominated (sex ratio at 2) in phage with Kingue (sex ratio at 1.3) and Bodian (sex ratio at 1.7) unlike Go which had a female predominance at 55\% [1] [4] [5]. Arterial hypertension was the most described risk factor $50.6 \%$ in line with Lanzy [6] and most of the African but also African-American studies on heart failure [7] [8] [9] [10] [11]. The history was chronic heart failure of hypertensive origin $14.6 \%$ and diabetes $6.6 \%$ according to Bodian and Sarra [1] [12].

The etiological factors of CRS are dominated by hypertensive dilated cardiomyopathy (46.6\%) and ischemic heart disease (20\%) in agreement with Bodian [1] and the rest of the literature.

In the majority of cases (72\%), the SCR was type 1 versus (97.22\%) for type 2 in Bodian [1], our study was carried out in a medical department where all the other medical specialties were there.

In our series, the picture of global heart failure (74.6\%) was the most common discovery method, consistent with the rest of the literature [12] [13] [14] [15] explaining the severity of cardio-renal syndrome. Renal damage was biologically constant with a mean creatinine clearance of $32 \mathrm{ml} / \mathrm{min}$. Doppler echocardiography noted dilation of the left ventricle associated with impaired systolic function $64 \%$ compared to $71 \%$ in Bodian [1].

This difference can be explained by the fact that our study took place in a medical service against the Dakar series in the cardiology service. We recorded a low case fatality rate of $10.6 \%$ compared to most of the literature due to the small sample size [1] [16] [17].

The limitations of our study:

The small size of our sample; financial difficulties and the security situation linked to the rebellion in the area prevented patients from being consulted the hospital.

\section{Conclusion}

Cardio-renal syndrome is a common feature in which mixed failure is observed 
in the unfavorable course of heart disease and nephropathy. Its prevalence is unfortunately underestimated in cardiological settings in Africa and in particular in Mali, hence the interest of a more advanced study.

\section{Recommendations}

We focus on raising public awareness and health workers on the regular and correct monitoring of high blood pressure.

At the level of political decision-makers: Reinforce accessibility to care.

Research: We believe that prospective and multicentre studies are necessary to better determine the prevalence of CRS in Africa and in Mali in particular.

\section{Acknowledgements}

We thank the management of the Tombouctou Hospital for completing the administrative and regulatory formalities for this work, as well as the patients for their trust.

\section{Conflicts of Interest}

The authors declare no conflicts of interest regarding the publication of this paper.

\section{References}

[1] Bodian, M., Thiaw, A., Sarr, S.A., Babaka, K., Aw, F., Ngaïde, A.A., Ndiaye, M.B., Kane, A., Jobe, M., Mbaye, A., Diao, M., Sarr, M. and Ba, S.A. (2017) Epidemiological Features of Cardiorenal Syndrome: A Study of 36 Cases in the Cardiology Department in Dakar. The Pan African Medical Journal, 28, 58. https://doi.org/10.11604/pamj.2017.28.58.10257

[2] Ronco, C., Kaushik, M., Valle, R., Aspromonte, N. and Peacock, W.F. (2012) Diagnosis and Management of Fluid Overload in Heart Failure and Cardiorenal Syndrome: The "5B" Approach. Seminars in Nephrology, 32, 129-141.

https://doi.org/10.1016/j.semnephrol.2011.11.016

[3] Heywood, J.T., Fonarow, G.C., Costanzo, M.R., Mathur, V.S., Wigneswaran, J.R., Wynne, J., et al. (2007) High Prevalence of Renal Dysfunction and Its Impact on Outcome in 118,465 Patients Hospitalized with Acute Decompensated Heart Failure: A Report from the ADHERE Database. Journal of Cardiac Failure, 13, 422-430. https://doi.org/10.1016/j.cardfail.2007.03.011

[4] Kingue, S., Dzudie, A., Menanga, A., Akono, M., Ouankou, M. and Muna, W. (2005) New Look at Chronic Heart Failure in Adults in Africa in the Era of Doppler Echocardiography: Experience of the Medical Department of the Yaoundé General Hospital. Ann Cardiol Angeiol (Paris), 54, 276-283.

[5] Go, A.S., Chertow, G.M., Fan, D., McCulloch, C.E. and Hsu, C. (2004) Chronic Kidney Disease and the Risks of Death, Cardiovascular Events and Hospitalization. The New England Journal of Medicine, 351, 1296-1305.

https://doi.org/10.1056/NEJMoa041031

[6] Lanzy, A., Voumbo Matoumona, Y.V.Y., Ondziel Opara, A.S., Niama, A.C., Banga Mouss, R.B., Ondongo Atipo, A.M., Dimi Nianga, Y., Odzébé, A.W.S. and Bouya, P.A. (2021) Epidemiology and Etiologies of Acute Obstructive Renal Failure at the 
University Teaching Hospital of Brazzaville. Health Sciences and Disease, 22, 98-102.

[7] Bivigou, E.A., Allognon, M.C., Ndoume, F., Mipinda, J.B. and Nzengue, E.E. (2018) Mortality Rate in Patients with Heart Failure at the Libreville University Hospital and Associated Factors. Pan African Medical Journal, 31, 27.

https://doi.org/10.11604/pamj.2018.31.27.13259

[8] Damasceno, A., Mayosi, B.M. and Sani, M. (2012) The Causes, Treatment, and Outcome of Acute Heart Failure in 1006 Africans from 9 Countries. Archives of Internal Medicine, 172, 1386-1394. https://doi.org/10.1001/archinternmed.2012.3310

[9] Karaye, K.M. and Sani, M.U. (2008) Factors Associated with Poor Prognosis among Patients Admitted with Heart Failure in a Nigerian Tertiary Medical Centre: A Cross-Sectional Study. BMC Cardiovascular Disorders, 8, Article No. 16.

https://doi.org/10.1186/1471-2261-8-16

[10] Makubi, A., Hage, C., Lwakatare, J., et al. (2014) Contemporary Aetiology, Clinical Characteristics and Prognosis of Adults with Heart Failure Observed in a Tertiary Hospital in Tanzania: The Prospective Tanzania Heart Failure (TaHeF) Study. Heart, 100, 1235-1241. https://doi.org/10.1136/heartjnl-2014-305599

[11] Thiam, M. (2003) Heart Failure in an African Cardiological Environment. Bulletin de la Société de Pathologie Exotique, 96, 217-218.

[12] Jouini, S., Manai, H., Slimani, O., Hedhli, H., Hebaieb, F., Mezghanni, M., Aloui, A. and Kaddour, R.B. (2019) Epidemiological and Prognostic Profile of Acute Heart Failure: Experience in the Emergency Department at the Charles Nicole Hospital of Tunis from 2013 to 2014. The Pan African Medical Journal, 33, 251.

https://doi.org/10.11604/pamj.2019.33.251.17207

[13] Adams, K.F., Fonarow, G.C., Emerman, C.L., LeJemtel, T.H., Costanzo, M.R., Abraham, W.T., et al. (2005) Characteristics and Outcomes of Patients Hospitalized for Heart Failure in the United States: Rationale, Design, and Preliminary Observations from the First 100,000 Cases in the Acute Decompensated Heart Failure National Registry (ADHERE). American Heart Journal, 149, 209-216.

https://doi.org/10.1016/j.ahj.2004.08.005

[14] Gheorghiade, M., Abraham, W.T., Albert, N.M., Greenberg, B.H., O'Connor, C.M., She, L., et al. (2006) Systolic Blood Pressure at Admission, Clinical Characteristics, and Outcomes in Patients Hospitalized with Acute Heart Failure. JAMA, 296, 2217-2226. https://doi.org/10.1001/jama.296.18.2217

[15] Nieminen, M.S., Brutsaert, D., Dickstein, K., Drexler, H., Follath, F., Harjola, V.-P., et al. (2006) EuroHeart Failure Survey II (EHFS II): A Survey on Hospitalized Acute Heart Failure Patients: Description of Population. European Heart Journal, 27, 2725. https://doi.org/10.1093/eurheartj/ehl193

[16] Mahon, N.G., Blackstone, E.H., Francis, G.S., Starling, R.C., Young, J.B., Lauer, M.S., et al. (2002) The Prognostic Value of Estimated Creatinine Clearance Alongside Functional Capacity in Ambulatory Patients with Chronic Congestive Heart Failure. Journal of the American College of Cardiology, 40, 1106-1113. https://doi.org/10.1016/S0735-1097(02)02125-3

[17] Yancy, C.W., Lopatin, M., Stevenson, L.W., De Marco, T. and Fonarow, G.C. (2006) Clinical Presentation, Management, and In-Hospital Outcomes of Patients Admitted with Acute Decompensated Heart Failure with Preserved Systolic Function: A Report from the Acute Decompensated Heart Failure National Registry (ADHERE) Database. Journal of the American College of Cardiology, 47, 76-84. https://doi.org/10.1016/j.jacc.2005.09.022 


\section{Survey Sheet No.......}

\section{Socio-Demographic Data}

Last name: First name: Sex:

Profession: Residence: Age:.

\section{Reason and Date of Hospitalization}

1) pattern:

2) Date: 3) Duration:

\section{Personal Background}
a) hypertension
d) Diabetes
b) chronic kidney failure
f) Heart valve disease
c) Heart failure
g) others:

\section{Cardiovascular Risk Factors}
1) Hypertension
4) Age $>60$ ans
2) Smoking
5) Obesity
3) Dyslipidemia
6) Famaly history of myocardial infarction

\section{Physical Examination}

1) General examination
a) Signsof congestions
b) others:
2) Cardiac Examination:

\section{Futher Examination}

1) EKG:
a) Heart rate:
c) Hypertrophies
b) Conduction desorders
d) Evidence of ischemia
2) Ultrasonic cardiography
a) kinematic: c) Sidewalls:
b) EF:
d) Péricardite
3) Biology
a) Blood count formula:
b) Urea:
b) Glycemia:
d) Creatininemia:
4) Kidney ultrasound:
a) Standard:
b) others:

\section{Diagnostic}
1) CRS Type
a) I c) III
e) $\mathrm{V}$
b) II
d) IV
2) Cardiomyopathies:
3) Kidney failure: 
B. Traoré et al.

4) others:

8. Evolution

$\begin{array}{lll}\text { 1) Favorable } & \text { 2) Death } & \text { 3) Refer }\end{array}$ 